\title{
Đánh giá khả năng đối kháng của các chủng Trichoderma spp. và Bacillus subtilis đối với chủng Pythium vexans gây bệnh chết nhanh trên hồ tiêu
}

\section{Evaluation of Trichoderma spp. and Bacillus subtilis against Pythium vexans causes root rot on black pepper}

\author{
Nguyễn Thị Ánh Nguyệt ${ }^{1 *}$, Lê Thị Mai Châm ${ }^{1}$, Trần Thùy Trang ${ }^{1}$, Dương Hoa Xô ${ }^{1}$ \\ ${ }^{1}$ Trung tâm Công nghệ Sinh học Thành phố Hồ Chí Minh, Việt Nam \\ *Tác giả liên hệ, Email: anhnguyet07s2@gmail.com
}

THÔNG TIN

DOI: $10.46223 /$ HCMCOUJS. tech.vi.13.1.452.2018

Ngày nhận: 10/07/2018

Ngày nhận lại: 04/09/2018

Duyệt đăng: 15/10/2018

Tù khóa:

Bacillus subtilis, bệnh chết nhanh trên tiêu, Pythium vexans, Trichoderma spp

\section{TÓM TẮT}

Pythium spp. được biết đến là một trong những tác nhân chính gây bệnh chết nhanh dẫn đến thiệt hại nặng nề về năng suất cây hồ tiêu (Shashidhara, 2007). Có nhiều biện pháp đã được áp dụng để phòng trừ bệnh chết nhanh trên hồ tiêu như hóa học, sinh học... Tuy nhiên, việc sử dụng thuốc hóa học thường cho hiệu quả thấp, độc hại và gây ô nhiễm môi trường nên biện pháp sinh học đang được chú trọng nhờ hiệu quả lâu dài và thân thiện với môi trường. Trong đó, Trichoderma spp. và Bacillus spp. từ lâu đã được chứng minh có khả năng đối kháng tốt với nấm Pythium spp. nhờ tiết một số loại enzyme ngoại bào như glucanase, chitinase, cellulose... (Amrita, Richa, Vijai, \& Harikesh, 2016; Anita, Aarti, Ashwin, Hariprasad, \& Shubhada, 2012; Najwa, Slim, \& Naïma, 2016). Nghiên cứu này cho thấy rằng, trong điều kiện in vitro, ở nồng độ $10^{6}$ bào tử động $/ \mathrm{ml}$, chủng Pythium vexans $\mathrm{P} 6$ có khả năng gây bệnh thối nhanh rễ tiêu với chỉ số gây hại và tỉ lệ hại cao nhất trong 11 chủng Pythium vexans. Ngoài ra, các kết quả thu được đã chứng minh 12 chủng Trichoderma spp. và 5 chủng Bacillus subtilis có khả năng đối kháng với chủng Pythium vexans $\mathrm{P} 6$ trong phòng thí nghiệm. Sau 6 ngày đồng nuôi cấy, phần trăm ức chế nấm bệnh của các chủng Trichoderma spp. đạt từ 40-90\%. Sau 8 ngày, hầu hết khuẩn lạc các chủng Trichoderma spp. đã ức chế hoàn toàn nấm bệnh. Bên cạnh đó, cả 5 chủng Bacillus subtilis đều có khả năng đối kháng với chủng nấm bệnh Pythium vexans P6. Tuy nhiên, tỷ lệ ức chế nấm bệnh của các chủng Bacillus subtilis chỉ đạt từ 22,69-27,67\% sau 6 ngày đồng nuôi cấy, thấp hơn so với các chủng Trichoderma spp.. 
Keywords:

Bacillus subtilis, Pythium vexans, root rot on black pepper, Trichoderma spp

\section{ABSTRACT}

Pythium spp. are well known as one of the main pathogens causing quick wilt disease of black pepper and severely reducing pepper yield (Shashidhara, 2007). Many treatment methods have been used to prevent root rot of black pepper such as chemical and biological methods. However, chemical treatment often has low effectiveness, harmfulness and environmentalunfriendliness. Meanwhile thanks to the long efficiency and ecofriendliness, biological agents have been increasingly using. In fact, Trichoderma spp. and Bacillus spp. were demonstrated that they possibly had the good antagonistic property against Pythium spp. because of their extracellular enzymes including glucanase, chitinase, cellulose... (Amrita et al., 2016; Anita et al., 2012; Najwa et al., 2016). The results of this study showed that in vitro the suspension containing $10^{6}$ zoospores $/ \mathrm{ml}$ of strain Pythium vexans $\mathrm{P} 6$ caused root rot of black pepper with the highest disease index and disease rate among 11 strains Pythium vexans. In addition, through this research antagonist effects of twelve Trichoderma strains and five Bacillus subtilis strains against Pythium vexans in vitro were also revealed. After 6 days of dual culture of Trichoderma spp. and Pythium vexans P6, the percentage of inhibition was from $40 \%$ to $90 \%$. Almost all strains of Trichoderma spp. could completely inhibit the growth of the pathogen after 8 days of dual culture. Besides, all five strains Bacillus subtilis revealed the growth inhibition against Pythium vexans P6 on agar dish; however, the proportion of inhibition on the development of pathogen was only $22,69 \%$ till $27,67 \%$ after 6 days of dual culture, lower than that of Trichoderma spp..

\section{Mở đầu}

Cây hồ tiêu (Piper nigrum L.) là cây công nghiệp nhiệt đới có giá trị kinh tế cao, đóng vai trò quan trọng trong nền kinh tế nước ta. Tuy nhiên, trong những năm gần đây, mặc dù diện tích hồ tiêu tăng dần theo từng năm nhưng năng suất tiêu lại có xu hướng giảm. Một trong những nguyên nhân chính gây thiệt hại nặng nề đến năng suất tiêu là bệnh chết nhanh hay còn gọi là bệnh thối rễ nhanh (Nguyen, 2015). Bệnh này do nhiều tác nhân, trong đó có Pythium spp., loài này thuộc lớp Oomycetes, tồn tại trong đất, có khả năng sinh bào tử động trong môi trường nước, có khả năng gây bệnh trên nhiều bộ phận của cây như rễ, gốc, thân, lá... và có cơ chế lây lan bệnh rất linh hoạt theo biến đổi thời tiết (Shashidhara, 2007). Ngoài ra, bệnh này rất khó nhận biết qua biểu hiện ngoại hình của cây trồng, thông thường khi nhận biết được thì bệnh đã ở giai đoạn rất nặng, rất khó xử lý, thậm chí có thể lây lan gây mất trắng toàn bộ năng suất. 
Do đó, việc nghiên cứu biện pháp phòng trừ bệnh chết nhanh trên cây tiêu là một vấn đề cấp thiết, mang tính thực tế cao.

Trichoderma thuộc lớp Ascomycetes, là loài nấm đất, thường được sử dụng để kiểm soát các bệnh do vi nấm gây ra trên cây trồng. Nấm Trichoderma đã được chứng minh có thể kiểm soát sinh học Alternaria, Colletotrichum, Phytophthora, Pythium, Rhizoctonia, Sclerotinia,Verticillium, ... Các cơ chế đối kháng của nấm này là ký sinh sợi nấm, tiết kháng sinh, cạnh tranh không gian và dinh dưỡng đồng thời kích hoạt cây chống lại mầm bệnh. Hơn nữa, nấm Trichoderma được cho là tiết các enzyme ngoại bào như glucanase, chitinase, ... có thể phân hủy sợi nấm bệnh do đó hạn chế được sự phát triển và xâm thực vào mô ký chủ (Amrita et al., 2016).

Bacillus được sử dụng để kiểm soát nhiều vi sinh vật gây bệnh cho cây trồng vì chúng có thể tiết nhiều chất kháng khuẩn hay kháng nấm, có thể cạnh tranh không gian và dinh dưỡng với vi sinh vật gây bệnh hay tăng sức đề kháng của cây trồng để chống lại các tác nhân gây bệnh (Approaches et al., 2001).

Nghiên cứu này được thực hiện nhằm đánh giá khả năng đối kháng của các chủng Trichoderma reesei, Trichoderma harzianum, Trichoderma virens và Bacillus subtilis đối với chủng Pythium vexans gây bệnh chết nhanh trên cây hồ tiêu.

\section{2. Đối tượng nghiên cứu}

Các chủng giống thuộc bộ sưu tập giống vi sinh vật của Trung tâm Công nghệ Sinh học Thành phố Hồ Chí Minh như trong Bảng 1.

\section{Bảng 1}

Danh sách các chủng vi sinh vật được sử dụng

\begin{tabular}{|c|c|c|c|}
\hline STT & Ký hiệu & Tên khoa học & Nguồn gốc \\
\hline 1 & $\mathrm{P} 1$ & Pythium vexans & \multirow{11}{*}{$\begin{array}{c}\text { Phân lập từ đất vùng rễ hồ tiêu bị bệnh } \\
\text { chêt nhanh thuộc huyện Bù Đốp, } \\
\text { tỉnh Bình Phước }\end{array}$} \\
\hline 2 & $\mathrm{P} 2$ & Pythium vexans & \\
\hline 3 & P3 & Pythium vexans & \\
\hline 4 & $\mathrm{P} 4$ & Pythium vexans & \\
\hline 5 & P5 & Pythium vexans & \\
\hline 6 & P6 & Pythium vexans & \\
\hline 7 & P7 & Pythium vexans & \\
\hline 8 & P8 & Pythium vexans & \\
\hline 9 & P9 & Pythium vexans & \\
\hline 10 & P10 & Pythium vexans & \\
\hline 11 & P11 & Pythium vexans & \\
\hline 12 & B1 & Bacillus subtilis & \multirow{2}{*}{$\begin{array}{c}\text { Phân lập từ đất thuộc huyện Chợ Gạo, } \\
\text { tỉnh Tiền Giang }\end{array}$} \\
\hline 13 & B2 & Bacillus subtilis & \\
\hline
\end{tabular}




\begin{tabular}{|c|c|c|c|}
\hline STT & Ký hiệu & Tên khoa học & Nguồn gốc \\
\hline 14 & B3 & Bacillus subtilis & \\
\hline 15 & B4 & Bacillus subtilis & \\
\hline 16 & B5 & Bacillus subtilis & \\
\hline 17 & $\mathrm{~T} 1$ & Trichoderma reesei & \multirow{2}{*}{$\begin{array}{c}\text { Phân lập từ đất thuộc vườn quốc gia Lò Gò } \\
\text { Xa Mát, tỉnh Tây Ninh }\end{array}$} \\
\hline 18 & $\mathrm{~T} 2$ & Trichoderma harzianum & \\
\hline 19 & $\mathrm{~T} 3$ & Trichoderma virens & \multirow{5}{*}{$\begin{array}{l}\text { Phân lập từ đất thuộc huyện Bù Gia Mập, } \\
\text { tỉnh Bình Phước }\end{array}$} \\
\hline 20 & $\mathrm{~T} 4$ & Trichoderma harzianum & \\
\hline 21 & T5 & Trichoderma harzianum & \\
\hline 22 & T6 & Trichoderma virens & \\
\hline 23 & $\mathrm{~T} 7$ & Trichoderma harzianum & \\
\hline 24 & $\mathrm{~T} 8$ & Trichoderma virens & \multirow{2}{*}{$\begin{array}{c}\text { Phân lập từ đất thuộc huyện Lộc Ninh, tỉnh } \\
\text { Bình Phước }\end{array}$} \\
\hline 25 & T9 & Trichoderma virens & \\
\hline 26 & $\mathrm{~T} 10$ & Trichoderma virens & \multirow{2}{*}{$\begin{array}{c}\text { Phân lập từ đất thuộc huyện Hớn Quản, } \\
\text { tỉnh Bình Phước }\end{array}$} \\
\hline 27 & T11 & Trichoderma virens & \\
\hline 28 & $\mathrm{~T} 12$ & Trichoderma harzianum & $\begin{array}{c}\text { Phân lập từ đất thuộc huyện Bù Đốp, tỉnh } \\
\text { Bình Phước }\end{array}$ \\
\hline
\end{tabular}

Nguồn: Kết quả phân tích dữ liệu của nhóm nghiên cứu

\section{Phương pháp}

\subsection{Chuẩn bị dịch huyền phù bào tử động (zoospore) của các chủng Pythium vexans}

Dịch huyền phù bào tử động của các chủng Pythium vexans được chuẩn bị theo phương pháp của Robert, Jean, và Lee (1995). Nuôi cấy các chủng Pythium vexans trên môi trường PCA trong 7 ngày ở nhiệt độ phòng. Dùng dao cấy vô trùng chuyển các tản nấm vào erlen chứa nước cất vô trùng, ủ trong 72 giờ ở nhiệt độ phòng. Sau đó, các erlene này được cho vào tủ lạnh $5^{\circ} \mathrm{C}$ trong 1 giờ để kích thích các túi bào tử giải phóng bào tử động. Lọc hỗn hợp qua vải để thu dịch huyền phù, sau đó xác định mật độ bào tử động trên buồng đếm hồng cầu (Robert et al., 1995).

\section{2. Đánh giá khả năng gây thối rễ nhanh của 11 chủng Pythium vexans ở điều kiện phòng thí nghiệm}

Thí nghiệm đơn yếu tố được bố trí theo kiểu hoàn toàn ngẫu nhiên (CRD gồm 12 nghiệm thức tương ứng với 11 chủng nấm bệnh và 1 nghiệm thức đối chứng). Mỗi nghiệm thức lặp lại 3 lần, mỗi lần lặp lại là một bộ rễ tiêu.

Thu nhận các bộ rễ tiêu từ những cây tiêu được chăm sóc trong điều kiện nhà kính, tránh làm tổn thương bộ rễ. Rửa sạch rễ dưới vòi nước, sau đó khử trùng với cồn $70^{\circ}$ trong 30 giây và rửa lại hai lần với nước cất. Tiến hành ngâm bộ rễ tiêu với $100 \mathrm{ml}$ dịch huyền phù bào tử động mật độ $10^{6}$ bào tử/ml (Ton, Ton, \& Le, 2015), sau 4 giờ lấy rễ ra đặt vào hộp nhựa tròn 
có sẵn bông thấm nước đã hấp khử trùng. Bao miệng hộp bằng giấy bạc, ủ ở nhiệt độ phòng. Đối với nghiệm thức đối chứng, thay dịch bào tử động bằng nước cất vô trùng.

Tiến hành lấy chỉ tiêu sau 5 ngày chủng bệnh. Đánh giá khả năng gây bệnh thối rễ nhanh trên rễ hồ tiêu của các chủng Pythium vexans dựa vào tỷ lệ hại, chỉ số hại và phân cấp hại đối với vi sinh vật gây bệnh ở rễ theo QCVN 01 - 172 như sau:

- Tỷ lệ hại $(\%)=\frac{\text { Số đơn vị mẫu điều tra bị hại }}{\text { Tổng số đon vị mẫu điều tra }} \times 100$

- Chỉ số hại $(\%)=\frac{\sum\left[\left(N_{1} \times 1\right)+\ldots+\left(N_{n} \times n\right)\right]}{N \times K} \times 100$

Trong đó:

$\mathrm{N}_{1}$ : là số mẫu điều tra bị hại ở cấp 1

$\mathrm{N}_{\mathrm{n}}$ : là số mẫu điều tra bị hại ở cấp $\mathrm{n}$

$\mathrm{N}$ : là tổng số mẫu điều tra

K: là cấp hại cao nhất của thang phân cấp

• Phân cấp hại đối với loài sinh vật gây hại gốc rễ

Cấp 1 (nhẹ): $\leq 1 / 3$ số rễ bị hại.

Cấp 2 (trung bình): > 1/3 - < 2/3 số rễ bị hại.

Cấp 3 (nặng): $\geq 2 / 3$ số rễ bị hại.

\section{3. Đánh giá khả năng đối kháng với chủng Pythium vexans P6 của 12 chủng Trichoderma spp. trong phòng thí nghiệm}

Thí nghiệm được tiến hành theo phương pháp đồng nuôi cấy như mô tả Iuliana và cộng sự (2017) gồm 13 nghiệm thức (12 chủng nấm Trichoderma spp. và 1 nghiệm thức đối chứng), mỗi nghiệm thức lặp lại 3 lần. Nuôi cấy các chủng Trichoderma spp. và chủng Pythium vexans P6 riêng biệt trong các đĩa Petri chứa môi trường PDA ở $25^{\circ} \mathrm{C}$. Sau 2 ngày, chuyển một khoanh hệ sợi Pythium vexans đường kính $5 \mathrm{~mm}$ sang đĩa Petri chứa môi trường $\mathrm{PDA}$; đồng thời, đặt một khoanh nấm Trichoderma sp. đường kính $5 \mathrm{~mm}$ ở phía đối diện của cùng đĩa Petri sao cho đối xứng nhau qua đường kính đĩa và cả hai cách mép đĩa $2 \mathrm{~cm}$. Đối với nghiệm thức đối chứng, chỉ cấy hệ sợi nấm bệnh. Nuôi cấy các đĩa Petri này ở $25^{\circ} \mathrm{C}$. Đo bán kính khuẩn lạc nấm bệnh ở các nghiệm thức 2 ngày/lần. Đánh giá tính đối kháng của chủng Trichoderma spp. với nấm bệnh dựa vào phần trăm ức chế theo công thức: $(\mathrm{C}-\mathrm{T}) / \mathrm{C} * 100$. Trong đó:

C: bán kính khuẩn lạc của nấm bệnh trong nghiệm thức đối chứng;

T: bán kính khuẩn lạc của nấm bệnh khi được nuôi cùng với Trichoderma spp. (Anita et al., 2012). 


\section{4. Đánh giá khả năng đối kháng với chủng Pythium vexans P6 của 5 chủng Bacillus subtilis trong phòng thí nghiệm}

Thí nghiệm được tiến hành theo phương pháp của Shouan và cộng sự (2010) gồm 6 nghiệm thức ( 5 chủng vi khuẩn Bacillus subtilis và 1 nghiệm thức đối chứng), mỗi nghiệm thức lặp lại 3 lần. Tiến hành nuôi cấy các chủng vi khuẩn Bacillus subtilis trên môi trường TSA và chủng Pythium vexans trên môi trường $\mathrm{PDA}$ ở $25^{\circ} \mathrm{C}$. Sau 2 ngày, chuyển một khoanh hệ sợi Pythium vexans đường kính $5 \mathrm{~mm}$ sang đĩa Petri chứa môi trường $\mathrm{PDA}$, sau đó cấy 1 đường vi khuẩn ở phía đối diện cách mép đĩa $2 \mathrm{~cm}$. Ở nghiệm thức đối chứng, chỉ cấy hệ sợi Pythium vexans. Nuôi cấy các đĩa Petri này ở $25^{\circ} \mathrm{C}$, đo đường kính nấm bệnh ở các nghiệm thức 2 ngày/lần. Đánh giá tính đối kháng của các chủng Bacillus subtilis với nấm bệnh dựa vào phần trăm ức chế theo công thức: $(\mathrm{C}-\mathrm{T}) / \mathrm{C} * 100$. Trong đó:

$\mathrm{C}$ : đường kính khuẩn lạc của nấm bệnh trong công thức đối chứng

T: đường kính khuẩn lạc của nấm bệnh khi đồng nuôi cấy với Bacillus subtilis (Shouan et al., 2010)

\section{Kết quả và thảo luận}

Đánh giá khả năng gây bệnh thối rễ nhanh của 11 chủng Pythium vexans trên rễ hồ tiêu ở phòng thí nghiệm.

\section{Bảng 2}

Kết quả khảo sát khả năng gây thối nhanh rễ hồ tiêu trong phòng thí nghiệm của 11 chủng Pythium vexans

\begin{tabular}{ccccc}
\hline STT & Chủng & Tỉ lệ hại (\%) & Chỉ số hại (\%) & Phân cấp bệnh \\
\hline 1 & P6 & 92.5 & 100 & $3,00^{\mathrm{a}}$ \\
2 & P2 & 70 & 91,67 & $2^{\mathrm{b}}$ \\
3 & P11 & 50 & 66,67 & $1,75^{\mathrm{bc}}$ \\
4 & P3 & 42.5 & 58,33 & $1,75^{\mathrm{bc}}$ \\
5 & P4 & 40 & 58,33 & $1,75^{\mathrm{bc}}$ \\
6 & P5 & 37.5 & 58,33 & $1,75^{\mathrm{bc}}$ \\
7 & P10 & 37.5 & 58,33 & $1,75^{\text {bc }}$ \\
8 & P1 & 32.5 & 50 & $1,50^{\mathrm{bcd}}$ \\
9 & P8 & 28.75 & 50 & $1,5^{\mathrm{bcd}}$ \\
10 & P9 & 25 & 41,67 & $1,25^{\mathrm{cd}}$ \\
11 & P7 & 13.75 & 33,33 & $1,00^{\mathrm{d}}$ \\
\hline \multicolumn{3}{c}{} \\
\hline \multicolumn{3}{c}{ Mức ý nghĩa }
\end{tabular}

Nguồn: Kết quả xử lý từ dữ liệu điều tra 

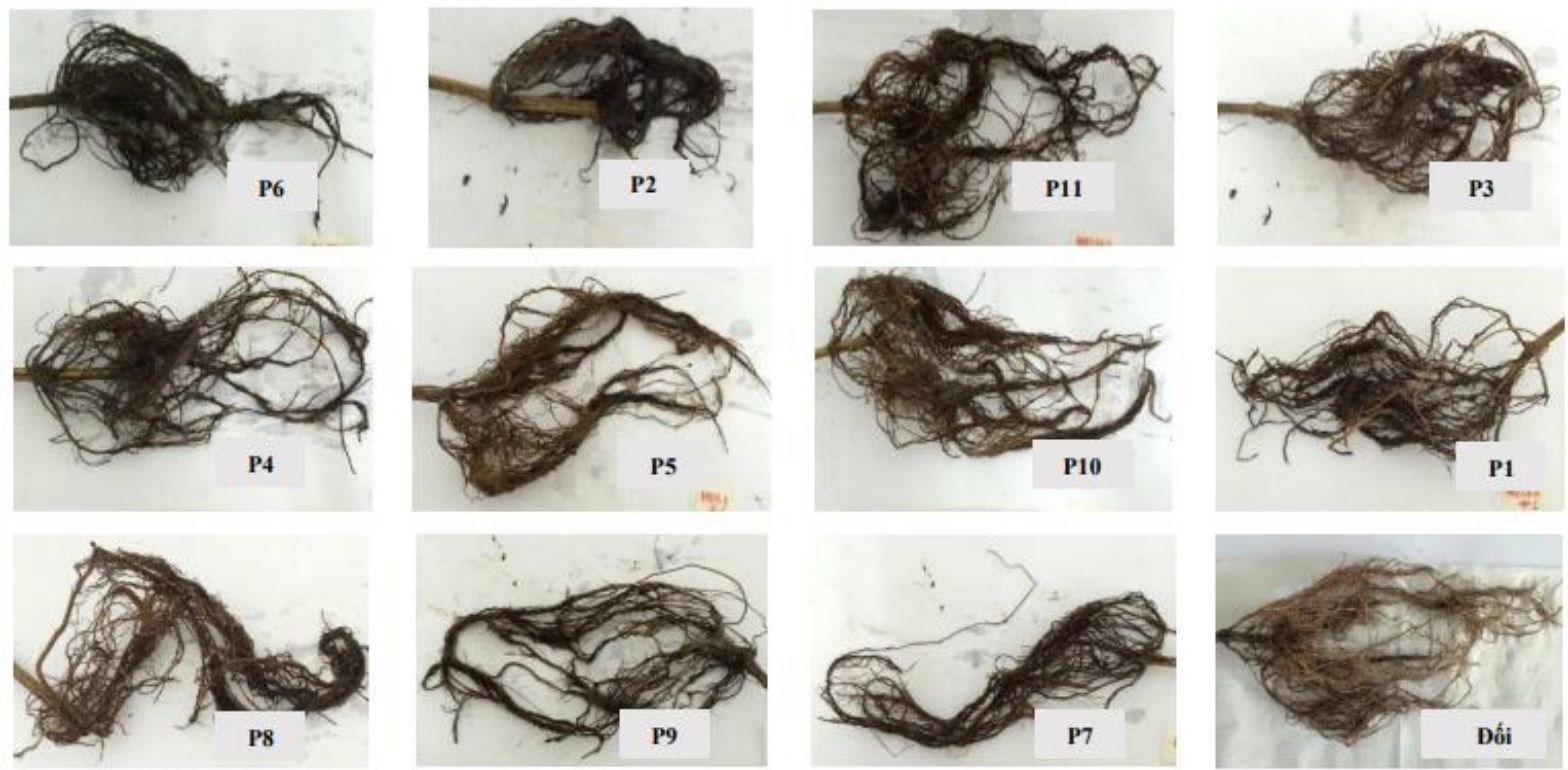

Hình 1. Triệu chứng thối rễ tiêu sau 5 ngày chủng bệnh với Pythium vexans

Dựa vào kết quả Bảng 2 cho thấy, sau 5 ngày chủng bệnh, tất cả 11 chủng Pythium vexans đều có khả năng gây bệnh thối nhanh rễ tiêu (Hình 1), tỷ lệ hại đạt từ 13,75-92,5\%. Trong đó, chủng P6 gây thối rễ với tỷ lệ hại đạt cao nhất $(92,5 \%)$ và chỉ số hại của chủng P6 cũng đạt $100 \%$, cao nhất so với các chủng Pythium vexans còn lại. Bên cạnh đó, khi phân cấp bệnh theo QCVN 01 - 172 thì rễ tiêu ở nghiệm thức P6 bị bệnh nặng nhất (khác biệt có ý nghĩa về mặt thống kê) (Hình 1). Trong khi đó, các bộ rễ tiêu ở nghiệm thức đối chứng vẫn giữ nguyên trạng thái ban đầu (Hình 1). Từ những kết quả này cho thấy, trong điều kiện phòng thí nghiệm, chủng P6 có khả năng gây bệnh thối nhanh rễ tiêu nặng nhất trong 11 chủng Pythium vexans khảo sát. Bên cạnh đó, kết quả thu được từ nghiên cứu này phù hợp với nhận định của Akira, Juan, Jose, và Tsuneo (1998) và Shashidhara (2007) khi cho rằng ngoài Phytopthora spp. thì loài Pythium spp. cũng có khả năng gây bệnh chết nhanh trên cây tiêu.

\section{1. Đánh giá khả năng đối kháng của Trichoderma spp. với chủng Pythium vexans} P6 trong phòng thí nghiệm

\section{Bảng 3}

Khả năng đối kháng của các chủng nấm Trichoderma spp. với chủng Pythium vexans P6 nuôi cấy trên môi trường PDA

Đơn vị tính: Phần trăm ức chế $(\%)$

\begin{tabular}{ccccc}
\hline & & \multicolumn{3}{c}{ Thò̀i gian (ngày) } \\
\cline { 3 - 5 } STT & Nghiệm thức & $\mathbf{4}$ & $\mathbf{6}$ & $\mathbf{8}$ \\
\cline { 3 - 5 } 1 & $\mathrm{~T} 1$ & $10^{\mathrm{e}}$ & $40^{\mathrm{f}}$ & $40^{\mathrm{b}}$ \\
2 & $\mathrm{~T} 2$ & $10^{\mathrm{e}}$ & $56,67^{\mathrm{cde}}$ & $100^{\mathrm{a}}$ \\
3 & $\mathrm{~T} 3$ & $10^{\mathrm{e}}$ & $68,33^{\mathrm{bc}}$ & $100^{\mathrm{a}}$
\end{tabular}




\begin{tabular}{ccccc}
\hline & & \multicolumn{3}{c}{ Thời gian (ngày) } \\
\cline { 3 - 5 } 4 & Nghiệm thức & $\mathbf{4}$ & $\mathbf{6}$ & $\mathbf{8}$ \\
\cline { 3 - 5 } 5 & T4 & $25^{\mathrm{de}}$ & $40^{\mathrm{f}}$ & $81,67^{\mathrm{a}}$ \\
6 & T5 & $46,67^{\mathrm{bc}}$ & $66,67^{\mathrm{bcd}}$ & $100^{\mathrm{a}}$ \\
7 & T6 & $30^{\mathrm{cd}}$ & $43,33^{\text {ef }}$ & $100^{\mathrm{a}}$ \\
8 & T7 & $30,33^{\mathrm{cd}}$ & $73,33^{\mathrm{b}}$ & $100^{\mathrm{a}}$ \\
9 & T8 & $51,67^{\mathrm{b}}$ & $56,67^{\text {cde }}$ & $100^{\mathrm{a}}$ \\
10 & T9 & $40^{\mathrm{bcd}}$ & $53,33^{\mathrm{def}}$ & $93,33^{\mathrm{a}}$ \\
11 & T10 & $70^{\mathrm{a}}$ & $90^{\mathrm{a}}$ & $100^{\mathrm{a}}$ \\
12 & T11 & $35^{\mathrm{bcd}}$ & $53,33^{\mathrm{def}}$ & $100^{\mathrm{a}}$ \\
\hline & T12 & $51,67^{\mathrm{b}}$ & $53,33^{\mathrm{def}}$ & $100^{\mathrm{a}}$ \\
\hline
\end{tabular}

Nguồn: Kết quả phân tích dữ liệu của nhóm nghiên cứu

Kết quả thu được ở Bảng 3 cho thấy, tất cả 12 chủng Trichoderma spp. đều có khả năng đối kháng với chủng Pythium vexans P6 trong điều kiện phòng thí nghiệm. Sau 4 ngày đồng nuôi cấy, phần trăm ức chế nấm bệnh đạt từ $10 \%$ (T1, T2, T3) đến $70 \%$ (T10). Khả năng ức chế nấm bệnh tăng dần theo thời gian, sau 6 ngày đồng nuôi cấy, phần trăm ức chế đạt từ 4090\%, trong đó chủng T10 đạt 90\% (khác biệt có ý nghĩa về mặt thống kê). Trong khi đó, theo kết quả nghiên cứu của Anita và cộng sự (2012), sau 6 ngày đồng nuôi cấy, phần trăm ức chế chủng Pythium vexans của các chủng Trichoderma spp. chỉ đạt từ 32,31-69,23\%. Trong nghiên cứu này, sau 8 ngày đồng nuôi cấy, hầu hết các chủng nấm Trichoderma spp. đã ức chế hoàn toàn với nấm bệnh, trong đó có chủng T10; trong khi đó ở nghiệm thức đối chứng, nấm bệnh vẫn sinh trưởng và phát triển tốt, phủ kín đĩa Petri (Hình 2). Từ kết quả này cho thấy, trong điều kiện phòng thí nghiệm, loài Trichoderma virens đối kháng với nấm Pythium vexans gây bệnh thối nhanh rễ hồ tiêu hiệu quả hơn 2 loài Trichoderma reesei và Trichoderma harzianum (khác biệt có ý nghĩa về mặt thống kê). Bên cạnh đó, những kết quả khả quan này cho thấy việc ứng dụng các chủng Trichoderma spp. trong việc phòng trừ bệnh do Pythium spp. gây ra hoàn toàn có cơ sở khoa học. 

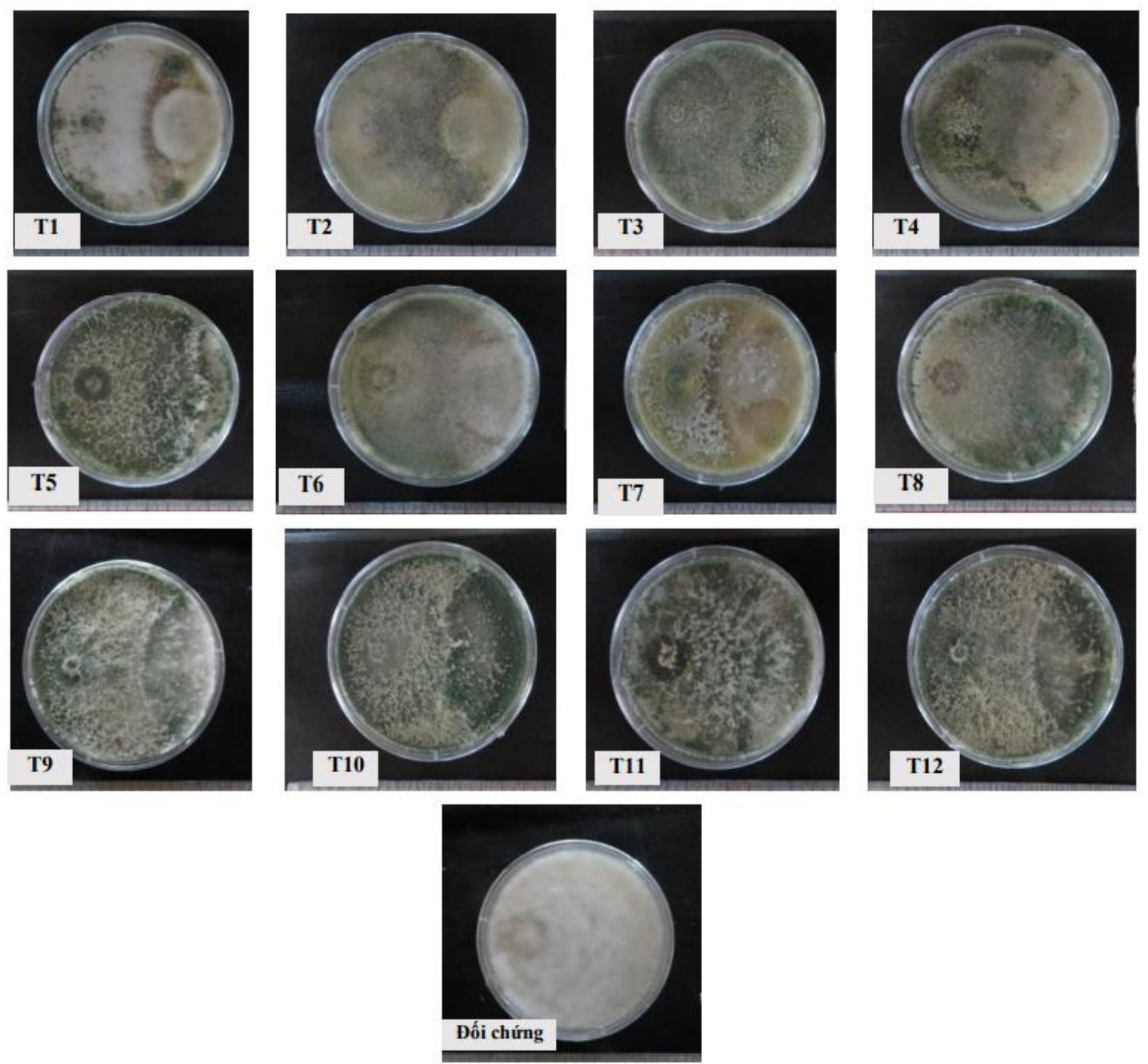

Hình 2. Khả năng đối kháng của 12 chủng Trichoderma spp. đối với chủng Pythium vexans P6 trong phòng thí nghiệm sau 8 ngày

\section{2. Đánh giá khả năng đối kháng của các chủng Bacillus subtilis với chủng Pythium vexans P6 trong phòng thí nghiệm}

Kết quả khảo sát trên môi trường PDA cho thấy, tất cả 5 chủng vi khuẩn Bacillus subtilis đều có khả năng đối kháng với chủng Pythium vexans $\mathrm{P} 6$; trong khi đó, ở nghiệm thức đối chứng nấm bệnh vẫn sinh trưởng và phát triển mạnh (Bảng 4 và Hình 3 ). Sau 2 ngày đồng nuôi cấy, cả 5 chủng vi khuẩn đã biểu hiện khả năng đối kháng với nấm bệnh, phần trăm ức chế đạt từ $0,75-3,24 \%$. Phần trăm ức chế này tiếp tục tăng ở thời điểm sau 4, 6 ngày nuôi cấy. Sau 6 ngày đồng nuôi cấy, phần trăm ức chế nấm bệnh của 5 chủng Bacillus subtilis đạt từ 23,3627,67\%. Và ở tất cả các thời điểm ghi nhận chỉ tiêu thì chủng CG11 có khả năng đối kháng tốt hơn các chủng vi khuẩn còn lại (khác biệt có ý nghĩa về mặt thống kê). Trong khi đó, theo kết quả nghiên cứu của Najwa và cộng sự (2016), sau 5 ngày đồng nuôi cấy, phần trăm ức chế các 
chủng Pythium spp. của vi khuẩn Bacillus spp. đạt từ 59-60\%. Tuy nhiên, kết quả này được tiến hành trên hai loài Pythium dissotocum và Pythium aphanidermatum, không phải loài Pythium vexans, đồng thời vi khuẩn Bacillus spp. của nghiên cứu này vẫn chưa xác định rõ tên loài. Ngoài ra, Najwa và cộng sự (2016) sử dụng phương pháp khác để đánh giá tính khả năng đối kháng của vi khuẩn Bacillus spp. và Pythium spp.. Cụ thể, hai khoanh nấm bệnh được cấy đối diện nhau trên cùng một đường kính đĩa Petri $90 \mathrm{~mm}$ chứa môi trường $\mathrm{PDA}$, cách nhau $15 \mathrm{~mm}$. Sau đó, cấy hai đường vi khuẩn Bacillus spp. $\left(10^{8} \mathrm{cfu} / \mathrm{ml}\right)$ trên đường kính vuông góc với nấm bệnh. Do đó, có thể vì một số lý do này nên có sự khác biệt về kết quả thu được giữa hai nhóm nghiên cứu.

\section{Bảng 4}

Khả năng ức chế của các chủng vi khuẩn Bacillus subtilis với chủng Pythium vexans P6 trên môi trường PDA

\begin{tabular}{|c|c|c|c|c|}
\hline \multirow{3}{*}{ STT } & \multirow{3}{*}{ Nghiệm thức } & \multirow{2}{*}{\multicolumn{3}{|c|}{$\begin{array}{c}\text { Đơn vị tính: Phần trăm ứ } \\
\text { Thò̀i gian (ngày) }\end{array}$}} \\
\hline & & & & \\
\hline & & 2 & 4 & 6 \\
\hline & B1 & $0,75^{\mathrm{c}}$ & $13,21^{\mathrm{b}}$ & $23,36^{\mathrm{c}}$ \\
\hline 2 & $\mathrm{~B} 2$ & $1,61^{b}$ & $11,85^{\mathrm{b}}$ & $24,83^{\mathrm{bc}}$ \\
\hline 3 & B3 & $3^{\mathrm{a}}$ & $11,12^{\mathrm{b}}$ & $26,10^{b}$ \\
\hline 4 & B4 & $2,96^{\mathrm{a}}$ & $12,45^{\mathrm{b}}$ & $22,69^{c}$ \\
\hline 5 & B5 & $3,24^{\mathrm{a}}$ & $15,84^{\mathrm{a}}$ & $27,67^{\mathrm{a}}$ \\
\hline $\mathrm{CV}(\%)$ & & 18,40 & 9,91 & 3,34 \\
\hline Mức ý nghĩa & & $*$ & $*$ & $*$ \\
\hline
\end{tabular}

Nguồn: Kết quả phân tích dữ liệu của nhóm nghiên cứu
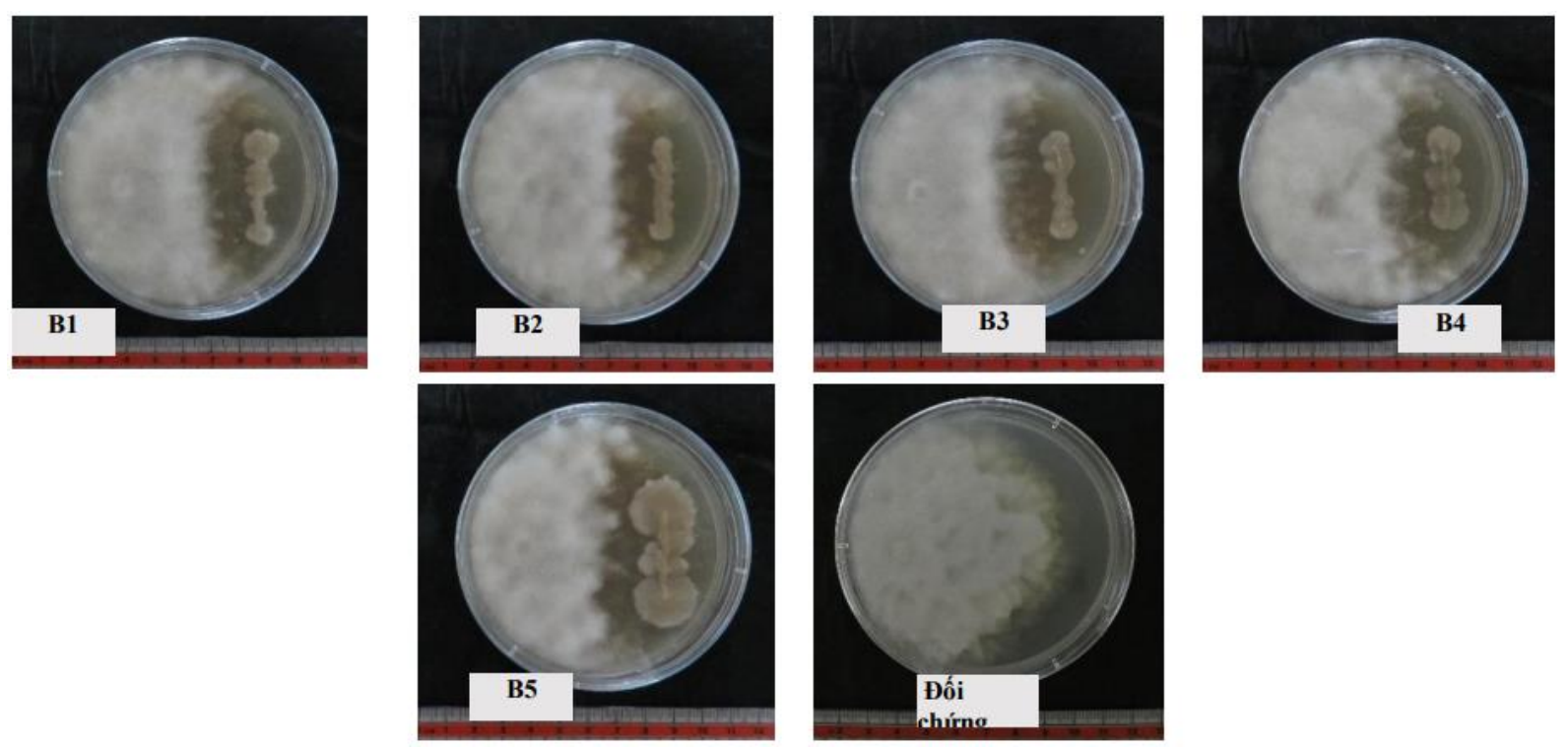

Hình 3. Khả năng đối kháng của 5 chủng vi khuẩn Bacillus subtilis đối với chủng Pythium vexans P6 sau 6 ngày 


\section{Kết luận}

Kết quả thử nghiệm khả năng gây hại của 11 chủng Pythium vexans cho thấy chủng Pythium vexans $\mathrm{P} 6$ có khả năng gây thối nhanh rễ tiêu mạnh nhất.

Mặc dù cả 3 loài Trichoderma spp. (Trichoderma virens, Trichoderma reesei và Trichoderma harzianum) đều có khả năng đối kháng với chủng Pythium vexans $\mathrm{P} 6$, tuy nhiên loài Trichoderma virens có khả năng ức chế nấm bệnh cao hơn. Thật vậy, chủng Trichoderma virens T10 có phần trăm ức chế Pythium vexans đạt $90 \%$ sau 6 ngày, cao hơn so với 11 chủng Trichoderma spp. còn lại (khác biệt có ý nghĩa về mặt thống kê). Trong 5 chủng vi khuẩn Bacillus subtilis, chủng B5 có phần trăm ức chế nấm bệnh đạt 27,67\% sau 6 ngày, cao hơn 4 chủng còn lại (khác biệt có ý nghĩa về mặt thống kê). Trong phạm vi nghiên cứu này, các chủng Trichodema spp. ức chế sự phát triển của nấm bệnh Pythium vexans $\mathrm{P} 6$ tốt hơn so với các chủng Bacillus spp. Cụ thể, sau 6 ngày đồng nuôi cấy, phần trăm ức chế chủng Pythium vexans $\mathrm{P} 6$ của các chủng Trichoderma spp. đạt 40-90\%, trong khi đó các chủng Bacillus subtilis chỉ đạt 22,6927,67\%. Kết quả này phù hợp với kết quả nghiên cứu của Christy, Tharmila, và Niranjan (2012).

\section{Tài liệu tham khảo}

Akira, M., Juan, D. D. M. F., Jose, L. G., \& Tsuneo, W. (1998). Root rots of black pepper cause by Pythium splendens in the Dominican Republic. Annals Phytophathological Society of Japan, 64(4), 303-306.

Amrita, S., Richa, R., Vijai, K. G., \& Harikesh, B. S. (2016). Chilli Anthracnose: The epidemiology and management. Frontiers in Microbiology, 7, Article 1527. doi:10.3389/fmicb.2016.01527.

Anita, P., Aarti, L., Ashwin, L., Hariprasad, P., \& Shubhada, M. (2012). In vitro antagonistic properties of selected Trichoderma species against tomato root rot causing Pythium species. International Journal of Science, Environment and Technology, 4(1), 302-315.

Approaches, T., Phenetics, N., Analyses, P., Metabolism, C., Repression, C., \& Metabolism, N. (2001). Biotechnology set (2nd ed.). Hoboken, NJ: Wiley.

Bộ NN và PTNT. (2014). Quy chuẩn kỹ thuật quốc gia về phuơng pháp điều tra phát hiện sinh vật gây hại cây hồ tiêu, QCVN 01 - 172 (Thông tư 16) [National technical regulation on methods of investigating and detecting harmful organisms of pepper plants, QCVN 01 172 (Circular 16)]. Retrieved May 1, 2018, from https://www.ppd.gov.vn/uploads/news/2014_06/172.pdf

Christy, J. E., Tharmila, S., \& Niranjan, K. (2012). Antagonistic activity of Trichoderma spp. and Bacillus spp. against Pythiumaphanidermatum isolated from tomato damping off. Archives of Applied Science Research, 4(4), 1623-1627.

Iuliana, R., Oancea, F., Belén, A., Trinidad, L. S., Calin, M., Aruxandei, D. C., ... Jecu, L. (2017). Evaluation of Trichoderma spp. as a biocontrol agent against Phytophthora parasitica. Scientific Bulletin Series F. Biotechnologies, 2017(21), 2285-1364. 
Izumitsu, K., Hatoh, K., Sumita, T., Kitade, Y., Morita, A., Gafur, A., ... Tanaka, C. (2012). Rapid and simple preparation of mushroom DNA directly from colonies and fruiting bodies for PCR. Mycoscience, 53(5), 396-401.

Najwa, B., Slim, T., \& Naïma, B. (2016). In-vitro evaluation of antagonists and fungicides in controlling citrus gummosis caused by phytophthora, phytopythium and pythium species in tunisia. British Microbiology Research Journal, 16(1), 1-14.

Nguyen, V. L. (2015). Spread of Phytophthora capsici in Black Pepper (Piper nigrum) in Vietnam. Engineering, 7, 506-513.

Perumal, M., Prabakaran, J. J., \& Kamaraj, M. (2013). Isolation and characterization of potential cyanide degrading bacillus nealsonii from different industrial effluents. International Journal of ChemTech Research, 5(5), 2357-2364.

Robert, L. P., Jean, R. B., \& Lee, C. C. (1995). Detection and Quantification of Phytophthora capsici in Soil. The American Phytopathology, 85(10), 1057-1063.

Shashidhara, S. (2007). Studies on foot rot of black pepper caused by Phytophthora capsici Leonian, emend, Alizedeh and Tsao. (Master's thesis). University of Agricultural Sciences, Dharwad, Indian.

Shouan, Z., Thomas, L., White, M. C. M., John, A. M., Joseph, W. K., \& Waldemar, K. (2010). Evaluation of plant growth-promoting rhizobacteria for control of Phytophthora blight on squash under greenhouse conditions. Biological Control, 53, 129-135

Ton, A. T., Ton, L. B., \& Le, D. D. (2015). Khảo sát khả năng chống chịu Phytophthora capsici của một số giống tiêu trong điều kiện phòng thínghiệm [Investigation of the resistance to Phytophthora capsici of some pepper varieties under laboratory conditions]. Retrieved May 20, 2018, from http://iasvn.org/tin-tuc/Khao-sat-kha-nang-chong-chiuPhytophthora-capsici-cua-mot-so-giong-Ho-Tieu-trong-dieu-kien-thi-nghiem-7595.html 